\title{
LA PERCEPCIÓN DE LOS SUCESOS CLIMÁTICOS EN UNA LOCALIDAD RURAL EN EL GOLFO DE MÉXICO
}

\author{
PERCEPTION OF CLIMATE EVENTS \\ IN A RURAL LOCATION IN THE GULF OF MEXICO
}

Felipe R. Vázquez Palacios

Centro de Investigaciones y Estudios Superiores en Antropología Social-Golfo

fevaz@msn.com

\section{RESUMEN}

El trabajo analiza lo que piensan las personas de edad avanzada en torno a los cambios climáticos de su localidad a partir de sus creencias religiosas, estilos de vida y su interacción social. Las preguntas que guían la investigación son: ¿Cómo se procesan los temores y las inseguridades que provoca la variabilidad climática entre los habitantes? ¿Cómo crean un ambiente de seguridad y una perspectiva hacia el futuro? El análisis detalla cuatro posturas: la evolucionista, la nostálgica, la conservadora y la resiliente, de donde se desprenden decisiones, acciones y formas de construir, narrar y darle significado a la relación del hombre con su entorno.

PALABRAS CLAVE: vejez, percepción, sucesos climáticos, fe.

\section{ABSTRACT}

This article analyzes what aging people think about the climate changes taking place in their region based on their religious beliefs, life styles and social interaction. The research questions are: How do inhabitants process the fears and insecurities caused by climate variations? How do they create an atmosphere of safety and a perspective regarding the future? The analysis details four positions: the evolutionist, the nostalgic, the conservative and the resilient perspectives that give rise to the decisions, actions and ways of constructing, narrating and giving meaning to people's relationship with their environment.

KEY WORDS: aging, perception, climate events, faith. 


\section{INTRODUCCIÓN}

Nadie se preocupa de vivir bien, sino de vivir mucho tiempo, cuando en poder de todos está vivir bien, en tanto que vivir largo tiempo en poder de ninguno SÉNECA 2000, Epístola a Lucilio

Toda persona y comunidad responden a su entorno y lo reflejan. La fe no es la excepción

JÜRGEN MOLTMANN

a variabilidad climática, ${ }^{1}$ según algunos especialistas (Tejeda et al. 1989, Welsh 2014), se ha convertido en un problema no solo de índole académica, sino también de interés público, y es que los eventos climáticos son cada día más frecuentes y peligrosos al poner a un número cada vez mayor de seres vivos en riesgo de sufrir algún daño. Fue en 1980 cuando los que estudian el clima y el medio ambiente determinaron las características de las sociedades y los entornos naturales que las hacen especialmente vulnerables o con capacidad de resiliencia a la variabilidad climática. ${ }^{2}$ En este contexto, los nortes o huracanes, granizadas, heladas, sequías, inundaciones provocadas por lluvias abundantes y atípicas constituyeron un recuento de eventos naturales que para los académicos eran parte de la naturaleza, mientras que para la mayoría de los habitantes vulnerados si bien los consideraban relacionados con la naturaleza, más lo asociaban con la divinidad.

Con el avance del conocimiento científico, la secularización y el racionalismo, las explicaciones sobre los eventos climáticos como castigos divinos fueron per-

\footnotetext{
1 Entiendo la variabilidad climática desde el actor social, por lo que cuando les pregunté a mis informantes sobre los cambios climáticos y sus efectos en la localidad, los sectores envejecidos me remitieron al aumento del calor, la escasez de lluvia, el aumento de vientos fuertes y precipitaciones, las bajas temperaturas, inestabilidad en las estaciones del año y las respectivas consecuencias en la salud y en su entorno físico y social. A ello me referiré cuando hable de variabilidad climática. Ahora este tipo de vulnerabilidad se enfoca a la relación que tienen las personas con su medio ambiente, en relación con la ocurrencia de desastres, o circunstancias que colocan al individuo o al grupo ante la posibilidad de ser afectados física y materialmente en sus personas y en sus propiedades, a lo que García (2014) ha llamado el telón de fondo del teatro en el cual se desarrolla el impacto de eventos que en ocasiones se transforman en desastres.

${ }^{2}$ Los especialistas se preguntaban si las sociedades son más o menos vulnerables que en el pasado y cuáles sectores de la sociedad vendrían siendo los más vulnerables a los cambios del medio ambiente.
} 


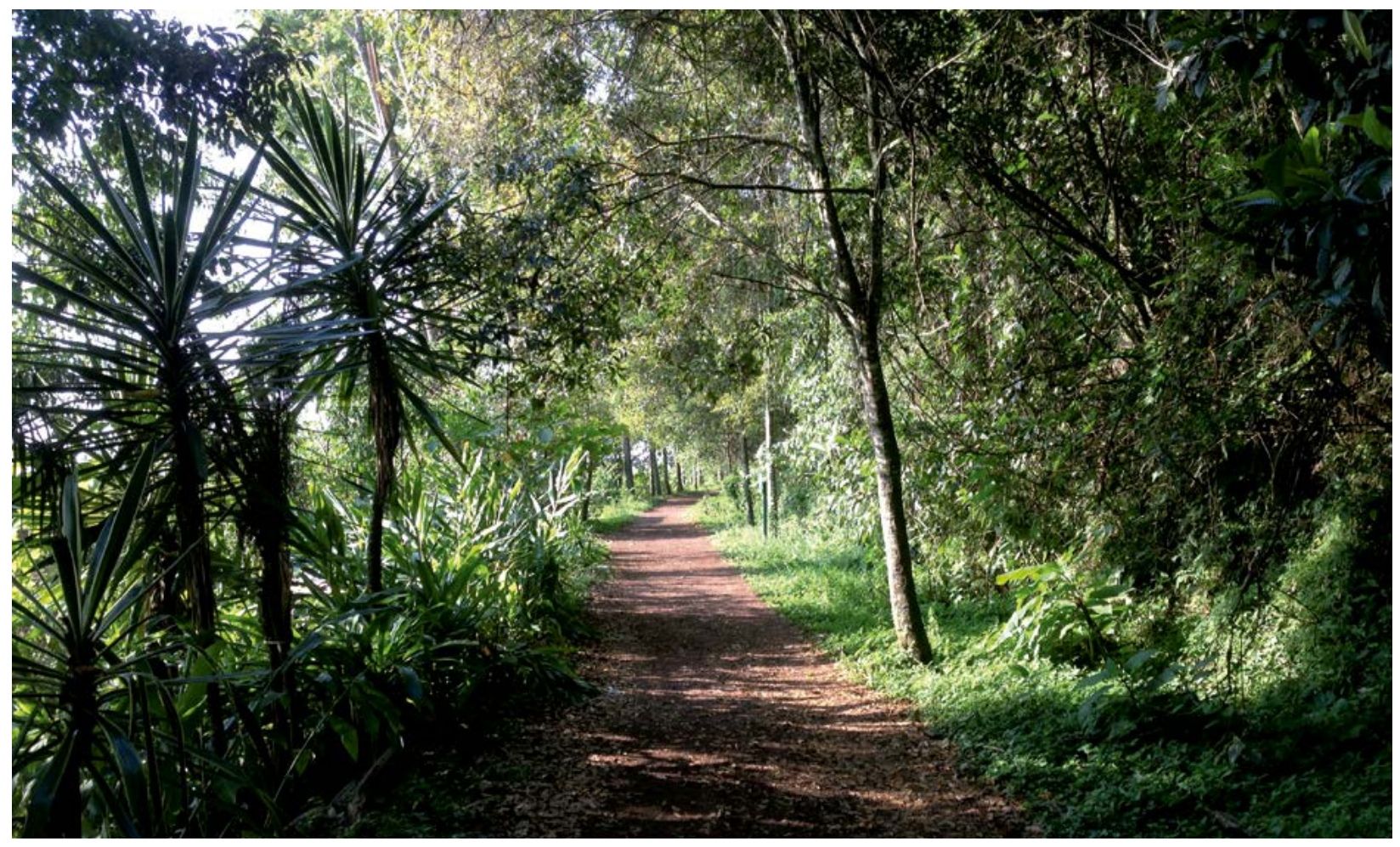

pescadores, comerciantes o trabajadores en general en las grandes ciudades (Aguilar 2009, Rodríguez y Shadow 2000 y Vargas 1997).

En este trabajo parto de la interrelación entre lo natural, lo social y lo religioso, ${ }^{5}$ donde el hombre es el protagonista que domina la naturaleza y la destruye. El que se apropia de su espacio y en un delicado equilibrio de factores materiales y sociales retroalimenta sus creencias, tradiciones, aspiraciones, necesidades, valores, genera sus ideas, opiniones y estrategias sobre la variabilidad climática; yendo de lo catastrófico y apocalíptico hasta una indiferencia total; o bien, desde una actitud emprendedora y de toma de conciencia, que busca mitigar y adaptarse a los cambios, hasta la de quienes se muestran escépticos sobre los datos ofrecidos y las predicciones de siniestros. Sostengo que la participación en acciones de prevención y conservación del entorno se da mediante la capacidad agencial que liga lo social con lo natural y religioso. Esta capacidad agencial la construyo tomando como referente a Long (2007:48); la defino como la capacidad que tiene el creyente de procesar la experiencia (de su vida individual y colectiva) para diseñar maneras de lidiar con la vida, aun bajo las formas más extremas. Siguiendo

\footnotetext{
${ }^{5}$ Orlando Olivares (2014) hace un estudio similar en sociedades indígenas de Venezuela donde el hombre al vivir integrado con la naturaleza encuentra una constante fuente de sabiduría, y sobre esa relación se estructuran las religiones indígenas, comparten muchos elementos y acusan influencias recíprocas, como lo evidencian diversas versiones de una misma historia.
} 
a Douglas (1986) señalo que cada sociedad está dispuesta a aceptar o evitar ciertos riesgos a partir de su adhesión a una determinada forma de sociedad. Lo que conlleva a ver a los habitantes del área de estudio (especialmente a las personas que llevan más de 20 años viviendo en el mismo lugar) como personas conscientes de los eventos climáticos que el lugar presenta y que, pese a esa situación en la que viven, están dispuestos a permanecer y enfrentar los riesgos de manera colectiva con sus propios medios y estrategias, creencias religiosas y demás formas culturales desarrolladas.

Sostengo como hipótesis que la percepción y la comprensión de los sucesos climáticos se va elaborando en la interacción tanto con el entorno como entre las personas involucradas y con otras personas; 6 luego entonces, la percepción se configura no solo por las experiencias físicas con el entorno, sino también con las creencias que como individuos han heredado de sus ancestros y por la experiencia que cada quien tiene en la participación directa con la naturaleza y la lucha contra todo aquello que la contamina y destruye. Digámoslo con otras palabras: las personas construyen sus explicaciones y toman conciencia de los diversos elementos y de las condiciones que generan la variabilidad climática, por medio del recorrido que ellos hicieron durante los años de vivir en su localidad, muchas veces orientados por su fe, en la cual han encontrado orden, seguridad y una forma eficaz para justificar y explicar las acciones y significaciones que tienen estos cambios y los efectos para el presente y especialmente para el futuro.?

El trabajo está basado en 100 cédulas de entrevista levantadas en la localidad de Carrizal (Municipio de Emiliano Zapata, en el centro de Veracruz) entre personas de más de 60 años, de las cuales 20 son mujeres entre 60 y 75 años y 30 de 75 y más años; 19 son hombres de 60 a 75 años y 31 más de 75 años. Todos ellos miembros de cuatro iglesias establecidas en esta localidad (34 católicos, 25 testigos de Jehová, 21 pentecostales y 20 cristianos de la iglesia Árbol de la vida). Trabajé con personas ancianas porque son los que tienen mayor experiencia y conocen el lugar que habitan, así como las creencias religiosas que practican; especialmente elegí a personas con más de 20 años viviendo en el mismo lugar;

\footnotetext{
${ }^{6}$ Hewitt sostenía que la vulnerabilidad es producto de las circunstancias en que las personas y sus propiedades entran en choque, y ante las cuales son incapaces o menos capaces que otros de enfrentarlas. Ello depende, en gran medida, de las condiciones sociales y materiales de vida así como de sus transformaciones (Hewitt 1997:167).

7 Ortega y Gasset (1914) decía: «yo soy yo y mi circunstancia y si no la salvo a ella no me salvo yo»; con ello quiero decir que los seres humanos construimos nuestro entorno con la adopción de explicaciones, creencias, experiencias, que nos dan significado de dónde estamos y por qué estamos aquí.
} 
además, profundicé ciertos datos y opiniones con informantes específicos o especialistas en el tema a tratar. El trabajo de campo lo realicé en dos temporadas, la primera en el invierno de 2014 y la segunda en el verano de 2015, utilizando el método etnográfico y construyendo narrativas con los informantes seleccionados. Además, se utilizaron cuestionarios con preguntas abiertas y conversaciones dirigidas tanto en grupos focales como de manera individual.

El trabajo está estructurado en tres bloques. En primer lugar, se hace una descripción del área de estudio; posteriormente, se exponen los resultados de las cédulas de entrevistas acompañándolas de entrevistas en profundidad para darle mayor solidez a la información. Finalmente se hacen algunas consideraciones y reflexiones al conjunto del trabajo.

\section{EL ÁREA DE ESTUDIO}

Villa Emiliano Zapata es una población del municipio homónimo, mejor conocida como Carrizal, en el centro de Veracruz, a una altura de 418 msnm. Según fuentes oficiales con información recabada desde hace más de 25 años, la localidad está clasificada como templada-húmeda-regular con una temperatura anual

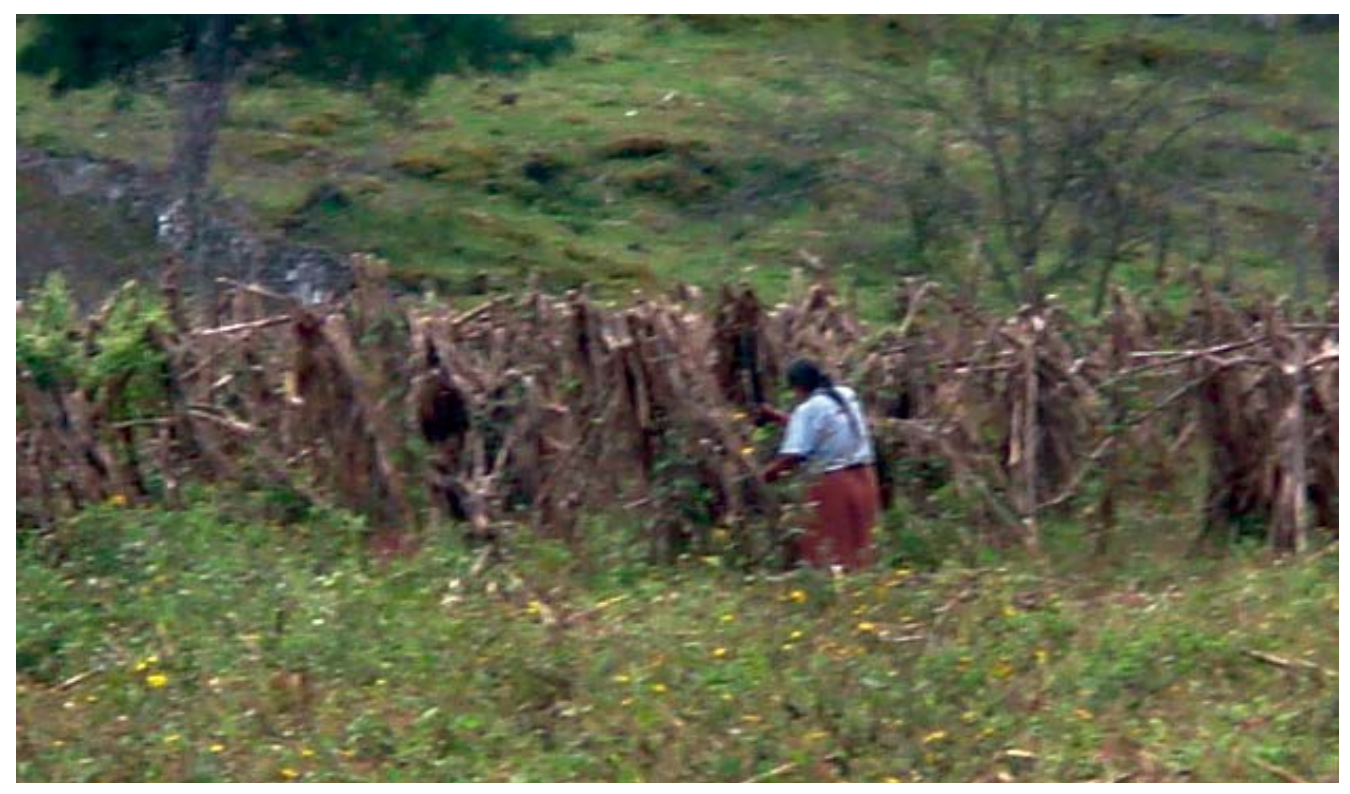


promedio de $25.2^{\circ} \mathrm{C}$, y una precipitación media anual de $2779.1 \mathrm{~mm}$. (Gobierno del Estado 1998 y Cuaderno Estadístico Municipal 1999). Presentado así sería un paraíso terrenal, pero actualmente, como veremos más adelante, el clima ha variado y se registran temperaturas por arriba de $35^{\circ} \mathrm{C}$ en temporada de calor y mucho frío en invierno, y con lluvia muy escasa. Esta población formó parte de un enorme latifundio conocido con el nombre de "Hacienda Plan del Río», propiedad de Ángel Trigos. El predio donde se fundó el poblado se conocía con el nombre de «Llano Grande» que era un paraje usado para el ganado de la hacienda. En el casco de esta pasaba el camino de carreta por donde transitaban las Ilamadas «diligencias» que cubrían el servicio de pasaje y carga y traslado de valores de Veracruz hacia la capital de la república.

Los primeros habitantes vinieron de la congregación cercana a la hacienda de Plan del Río, y de ahí emigraron a este lugar durante la estancia de los campamentos de trabajadores de las vías del tren. Se establecieron con carpas donde pusieron venta de alimentos para funcionarios, técnicos y obreros de las compañías constructoras, «cuadrilleros» que trabajaron en la construcción del ferrocarril interoceánico México-Jalapa-Veracruz, allá por los años 1890 y 1893. Los lugareños señalan que la llegada del tren trajo alegría al pueblo, pues al instalarse una estación no solo movilizaba pasajeros, sino mercancías y el agua para el uso de las máquinas y el servicio del ferrocarril. ${ }^{8}$ El tren funcionó sin interrupciones hasta 1997, cuando se privatizo, dejó de funcionar con pasajeros y se dedicó exclusivamente al transporte de carga.

Entre los años de 1918 a 1923, los lugareños se organizaron para pedir tierras, pero fracasaron. Tuvieron que esperar hasta 1942 para que 356 ejidatarios recibieran la dotación definitiva. Ese hecho dio arraigo a los pobladores, quienes continuaron cultivando maíz, frijol y chile, plantaron tamarindo, mango, papaya, limón, naranja, zapote mamey, zapote chico, guanábana y calabaza. «Todo se daba pese a que eran tierras sin riego. Había muchos carrizos, ahora es difícil ver uno» (Eustaquio, 75 años).

\footnotetext{
${ }^{8}$ A orillas de las vías se encontraba un tinaco gigante en el que se almacenaba agua para el consumo de la estación y los pobladores, y era rellenado cada vez que los encargados lo consideraban necesario. Las pipas cargaban en este lugar y después distribuían el vital líquido a los pobladores. Había veces que la gente tenía ganas de consumir agua fresca y esperaban el tren para que se las proporcionara. Aguardaban a la orilla de la vía con cubetas o recipientes. No fue hasta 1986 cuando se hicieron los trabajos de instalación de suministro a las viviendas. Una asociación conformada por habitantes del pueblo cobraba a los pobladores una cuota fija por este servicio a cambio de hacerse cargo del mantenimiento.
} 
Los ahora ancianos organizaban sus actividades alrededor de estos cultivos dependiendo de las temporadas de siembra y cosecha. Solo había una cosecha de maíz por año y se sembraban generalmente dos hectáreas. De una hectárea se obtenían alrededor de dos toneladas de maíz, con lo cual se tenía garantizado el consumo familiar. Actualmente los ejidatarios oscilan en edades que van de los 40 a los 80 años.

Observé que cuando se refieren al "antes» de sus vidas, generalmente hacen alusión a un periodo que puede ir de 1940 a 1980. La vida en Carrizal estaba marcada muy bien por las estaciones del año. Una informante lo describe así:

Recuerdo cómo me ilusionaba en la primavera con ir al río, mi mamá nos llevaba a lavar la ropa allá, ya que el agua escaseaba por el calor, especialmente en mayo y junio, después venían las lluvias y ya no podíamos ir al río, porque este crecía y se volvía muy peligroso, arrasaba con árboles, piedras y todo lo que estaba en su cauce. Después vendrían los nortes, mi papá nos hacía papalotes, los cuales empinábamos y nos divertíamos mucho, especialmente en Todos Santos en noviembre. A finales de este mes, empezábamos a sentir el frío, la neblina, las posadas. Todos estábamos acostumbrados cada año a estos cambios en el clima, no nos tomaban por sorpresa, la gente sabía que debía prepararse para los nortes, para el frío, para el calor, para las lluvias, todo estaba planeado. Ahora el tiempo se ha vuelto loco y nosotros más [risas]... (Mary, 84 años, católica).

Para la década de 1950 el poblado tenía una primaria (actualmente hay dos y dos preescolares) y para 1968, telesecundaria. ${ }^{9}$ Ahora existen tres preparatorias que cubren la demanda de los poblados circunvecinos. La luz eléctrica se instaló en 1957, mientras que el agua potable se introdujo en 1986. ${ }^{10}$ En 1970 se inauguró la clínica de salud del Instituto Mexicano del Seguro Social. ${ }^{11}$

Las enfermedades más recurrentes en las personas de la tercera edad son diabetes, hipertensión, especialmente en mujeres, dolores articulares, infecciones

\footnotetext{
${ }^{9}$ La primera primaria se llamó «Felipe Carrillo Puerto»; la secundaria, «José Calazán León», esto último en homenaje al jefe de estación de ferrocarril de la comunidad, ya que era apreciado por todos los habitantes y se le conocía como un hombre bueno y que no le negaba la ayuda a nadie.

${ }^{10}$ En 1994 se gestionó el servicio de recolección de basura, pero algunas personas la siguen tirando o quemando, lo cual ocasiona que con frecuencia se tapen las alcantarillas y cuando llueve se generan inundaciones. Otro de los principales problemas en esta localidad es que la vieja estación de ferrocarril se ha convertido en un edificio abandonado que sirve de baño, motel y sitio para drogarse.

${ }^{11}$ La clínica presta atención de lunes a viernes de 9:00 de la mañana a 2:00 de la tarde, cuenta con un médico general y dos enfermeras, una que cubre de lunes a viernes y la otra el fin de semana.
} 
respiratorias y cáncer de mama. Actualmente, con el aumento del calor, en los últimos cinco años se ha incrementado la proliferación del zancudo, sin que hasta ahora se haga alguna campaña para combatirlo; solo se llevan a cabo fumigaciones cuando los casos de dengue se vuelven frecuentes.

Políticamente se considera una población priista, donde solo una vez ha ganado el PAN. ${ }^{12}$ En la oficina del Comisariado ejidal hay reuniones cada dos meses para informar sobre algún programa de gobierno, o sobre las faenas que se deben hacer como servicio social. La localidad cuenta con 11270 habitantes, que distribuyen sus viviendas en 92 calles, divididas en siete colonias en una planicie que cuando llueve no permite correr el agua y al estancarse provoca charcos con lodo que abarcan toda la calle y hacen peligroso el tránsito, además de provocar criaderos de mosquitos y el riesgo de enfermedades como el dengue y el chikunguña. Las casas son de concreto en muros y pisos, con puertas y ventanas de fierro o madera y techos de lámina y colado de losa; cada una dispone de un corredor techado como estancia (ellos le llaman corredor) donde colocan sus mecedoras de madera o de plástico; generalmente hay un árbol de sombra para sentarse y disfrutar el aire fresco del atardecer en temporada de calor. «Me baño y me vengo a sentar aquí porque entra el aire fresco y aquí me estoy sentada, porque en mi cuarto el calor no se aguanta» (Francisco, 83 años, pentecostal).

Al interior de las viviendas, un cuarto grande sirve de dormitorio para toda la familia; la cocina es un pequeño jacal, a un costado de la casa, en donde están un fogón, una mesa y sillas de madera; en la cocina sobresalen ollas y cazuelas de barro ahumadas, que cuelgan de clavos u horcones; pueden verse también varios recipientes de plástico en donde se almacena el agua que se utiliza para hacer la comida. Cuentan con un baño ubicado afuera, a unos siete metros de la casa; algunos de estos baños tienen fosas sépticas y otros son letrinas construidas con horcones de madera, cubiertos de plástico opaco a su alrededor. Hay varias casas que ya tienen su baño integrado en los cuartos que componen la construcción.

Actualmente $40 \%$ de la población vive de la actividad agrícola, que combinan en $30 \%$ con la albañilería, ${ }^{13}$ con la ganadería en $20 \%$ y $10 \%$ en uno que otro

\footnotetext{
${ }^{12}$ Anteriormente se elegía al agente municipal llegando a un común acuerdo por medio de una asamblea. Hoy los candidatos hacen su planilla y se registran ante las autoridades correspondientes y se decide mediante el voto.

${ }^{13}$ Los campesinos hacen frente a las sequías yéndose a trabajar de albañiles al puerto de Veracruz, aunque también lo hacen a ciudades pequeñas como Cardel, Rinconada y Coatepec, entre otras. Este oficio les permite una buena movilización, especialmente cuando les falta lluvia para su cosecha o no llega el volumen que esperaban. Por medio de la albañilería es como gran parte de las familias del lugar han podido resolver sus problemas económicos.
} 
trabajo informal. Los programas del gobierno federal que llegan a esta localidad son el de Oportunidades, el de Pensión para adultos mayores de 65 y más (con 233 beneficiarios que reciben un apoyo de 1400 pesos cada dos meses), el Seguro popular (les da sus consultas y medicamentos gratis), y Procampo (que les proporciona 1300 pesos por hectárea para que puedan seguir cultivando la tierra, hay 200 ejidatarios inscritos). Aún no llega el programa Cruzada Nacional Contra el Hambre y poco se escucha de Prospera; algunos se están informando para obtener el apoyo, otros ya metieron sus documentos, pero no les han resuelto.

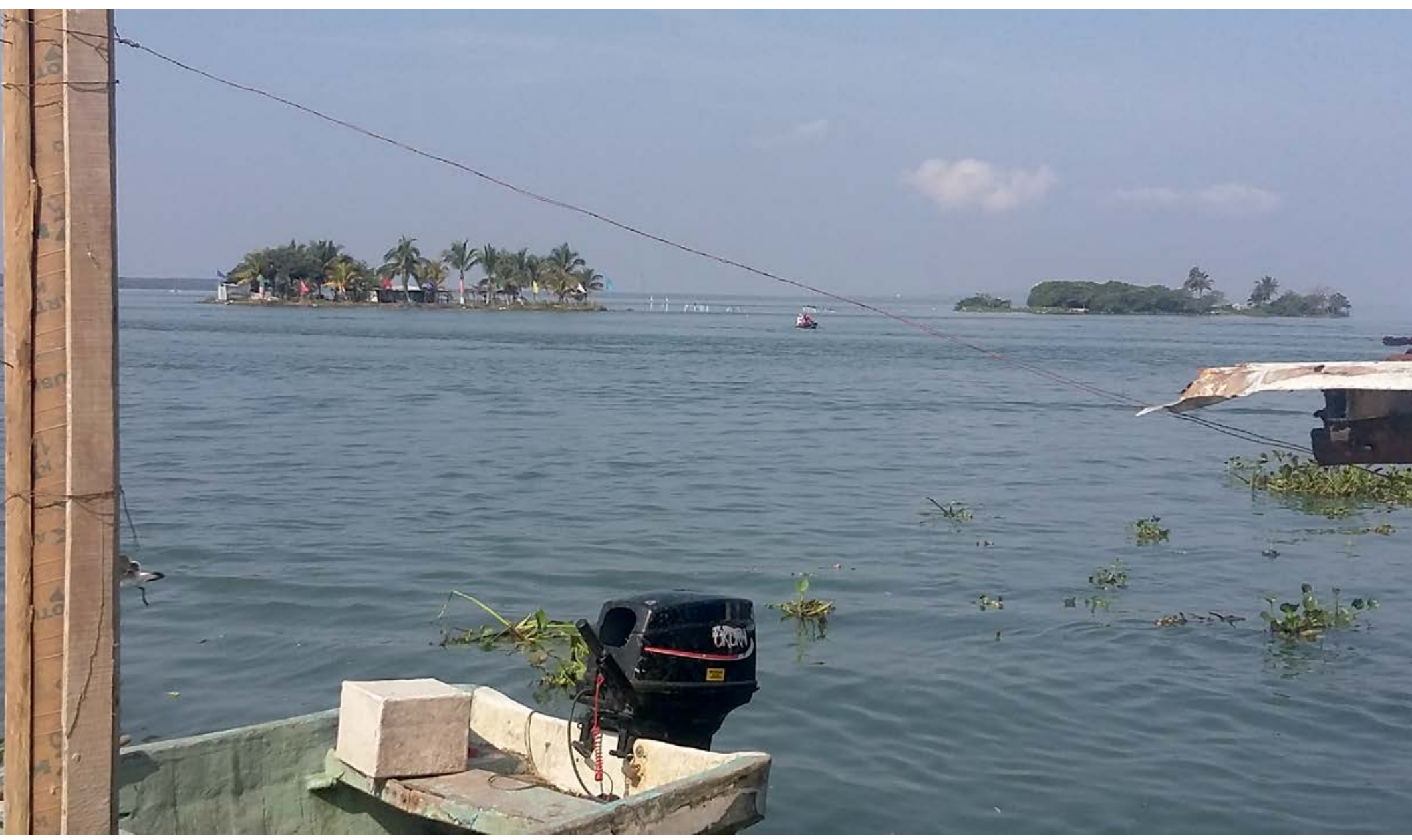

La carretera con destino a los Baños El Carrizal, ${ }^{14}$ de aguas termales, pasa en medio del poblado. Eso ha permitido el establecimiento de pequeñas tiendas de abarrotes y de alimentos a la orilla de la vía, así como el asentamiento de vi-

${ }^{14}$ Cuentan los ancianos que a los Baños del Carrizal se le conocía como: Río Grande, «pero con los años eso de grande ya no le queda nada, ya que solo crece cuando hay exceso de lluvias». 
viendas lujosas que son propiedad de personas «de fuera» que la utilizan como casas de campo y hoteles. En el poblado hay tres iglesias católicas, que tienen como santo patrón a San José, cuya fiesta es el 19 de marzo; otras fiestas son el 12 de diciembre, y la de Todos los santos, en noviembre. Hay dos agrupaciones de Alcohólicos Anónimos, tres iglesias evangélicas del Movimiento de Iglesias Evangélicas Pentecostal Independiente que llegó a la localidad en 1930; los testigos de Jehová aparecen en 1987 y el grupo de la iglesia cristiana, Árbol de la vida, en 1965. No encontré en mi estancia conflictos graves entre los miembros de estas diversas agrupaciones religiosas.

Uno de los temores que persisten entre los pobladores del lugar es el de estar tan cerca (escasos 40 kilómetros) de la nucleoeléctrica de Laguna Verde. Ellos han oído mucho de que las radiaciones harán a los pobladores ser más propensos al cáncer; además, están conscientes de que corren un riesgo real de sufrir problemas graves no solo en su salud sino en sus parcelas y casas...

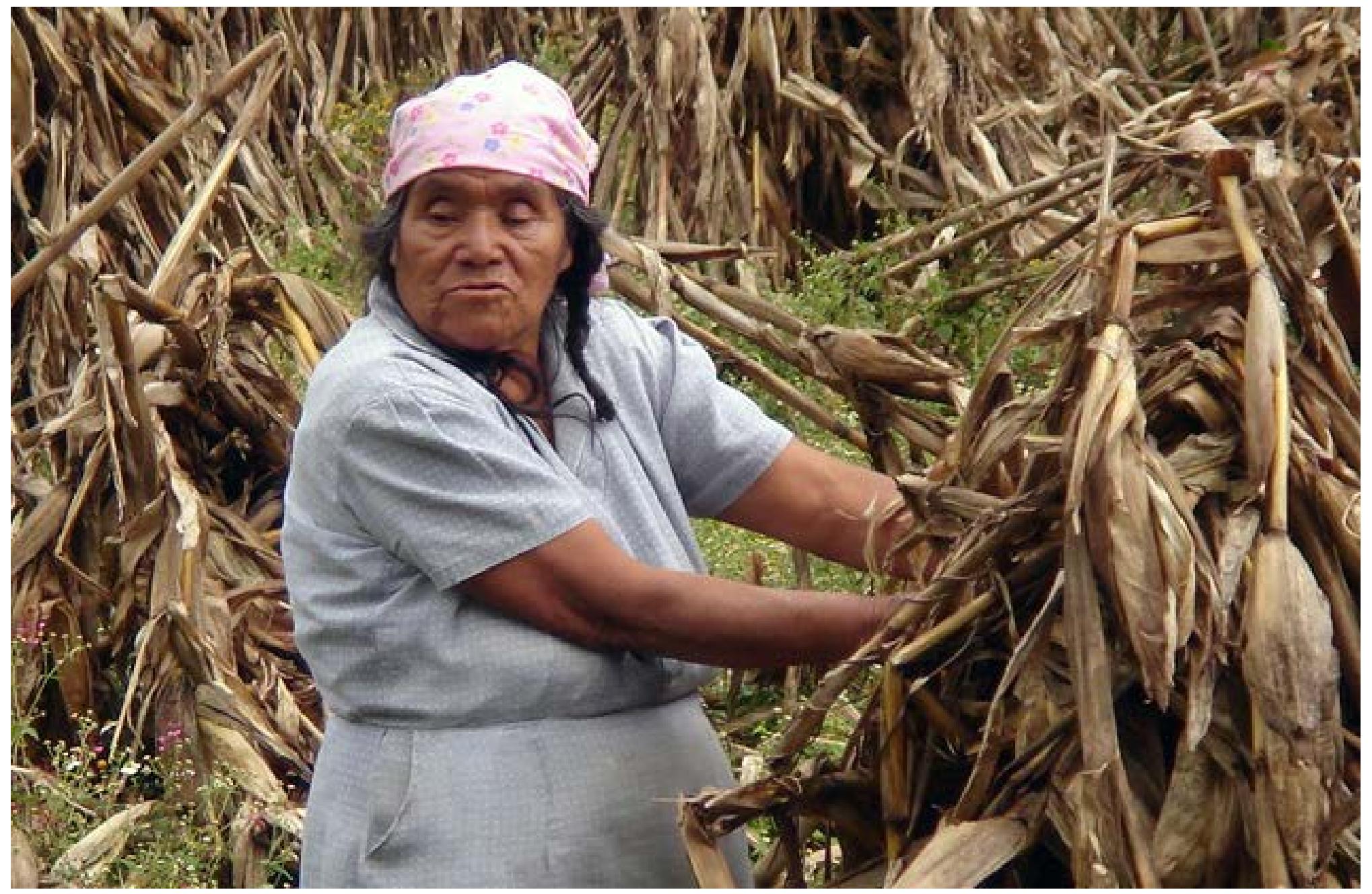


...si llega a explotar la nucleoeléctrica, volaría Veracruz, Xalapa, Perote, Puebla y ya ni se diga lo que le quede cerca. Es por eso que cuando nos enteremos de que se iba a instalar, todos estábamos en contra y en cada esquina pusimos carteles que decían 'NO A LA LAGUNA VERDE' pero pues al gobierno no le importó la gente sino el dinero, e ignoraron nuestra protesta y ahora está la nucleoeléctrica. Aunque prometieron que pondrían personal capacitado para que no haya riesgos desagradables, pero sea como sea no es necesario que explote para que cause daño sino con existir ya está contaminando y dañando no solo el ambiente sino a la misma gente (Alberto, 67 años, católico).

La planta tiene funcionando 37 años y aún sigue alimentando de energía eléctrica a todo México, incluso a Centroamérica. Pero para los lugareños el centro de preocupación no es la nucleoeléctrica, sino la obtención del agua, «pues es la vida», por eso piensan que cuando esta se acabe en la tierra los dirigentes del mundo «traerán agua de otro planeta para poder vivir y nos la venderán muy cara porque todos quieren hacer negocio» (Ramón, 68 años, católico).

\section{PERCEPCIONES SOBRE LA VARIABILIDAD CLIMÁTICA}

Los efectos de la variabilidad climática según mi trabajo de campo se han dejado sentir en el área de estudio en los sectores envejecidos básicamente en: a) la salud, b) las prácticas agrícolas y c) los estilos de vida cotidiana. ${ }^{15}$

a) En la salud, según los que han vivido por más de 40 años en la localidad, afirman que debido al calor cada vez más intenso, se fatigan mucho más, a veces hasta se les dificulta el respirar; su presión les tiende a bajar constantemente; incluso, han experimentado que sus padecimientos, malestares o dolores se intensifican con el calor. ${ }^{16} \mathrm{Y}$ aún más si hay cambios bruscos de temperatura, pues: "Cada rato estamos con la pinche gripa y la tos; enfermedades estomacales, calenturas, dolores de cabeza, salpullido o vómitos, el dengue» (Fonsa, 77 años, católica). ${ }^{17}$

\footnotetext{
${ }^{15}$ Vázquez et al. (2013) informan que la mayor percepción que las personas tienen en cuanto a los efectos del cambio climático es en la salud.

${ }^{16}$ En Europa los cambios bruscos en la temperatura fueron causa de enfermedades cardiovasculares, cerebrovasculares y respiratorias promotoras de la mayoría de muertes en 2003 (De Celis et al. 2012:8,11). Asimismo, el calor provoca que los alimentos se descompongan aceleradamente y propician la presencia y multiplicación de microorganismos, incluso en el agua de beber, lo que en los seres humanos puede provocar intoxicaciones.

${ }^{17}$ El dengue hasta hace algunos años tenía una distribución muy limitada y su reproducción era poco frecuente; ahora, el calor ha favorecido su reproducción y últimamente se oye hablar del chikunguña, al parecer una variante del dengue.
} 
Dependiendo del clima, ancianos y ancianas se quejan de su columna, sus rodillas, sus reumas, artritis o dolores musculares en la espalda y brazos, muchas de estas molestias las atribuyen a que están expuestos a los rayos del sol y el cuerpo se calienta, y al cambiar el tiempo o simplemente al pasar a la sombra, sus cuerpos no se enfrían como debe ser. Ellos saben perfectamente que no se deben bañar después de haber trabajado bajo los rayos del sol, hasta que su cuerpo haya vuelto a su temperatura normal de $37.5^{\circ} \mathrm{C}$. Una cuestión interesante que observé en las entrevistas fue que más de las tres cuartas partes de los entrevistados hicieron hincapié en que el aumento del calor se viene sintiendo desde hace 20 años para acá y que en los últimos ocho y cinco años es cuando más han sentido sus efectos. Aun los que gozan de salud aseguran que han sentido que el calor se ha acrecentado especialmente en los meses de abril, mayo y junio. Pese a que los informantes afirman que siempre ha hecho calor en la localidad, este no se sentía tan intenso como ahora: «Nos fatigamos con cualquier actividad y hay andamos como animalitos buscando la sombra» (Pedro, 69 años, testigo de Jehová).

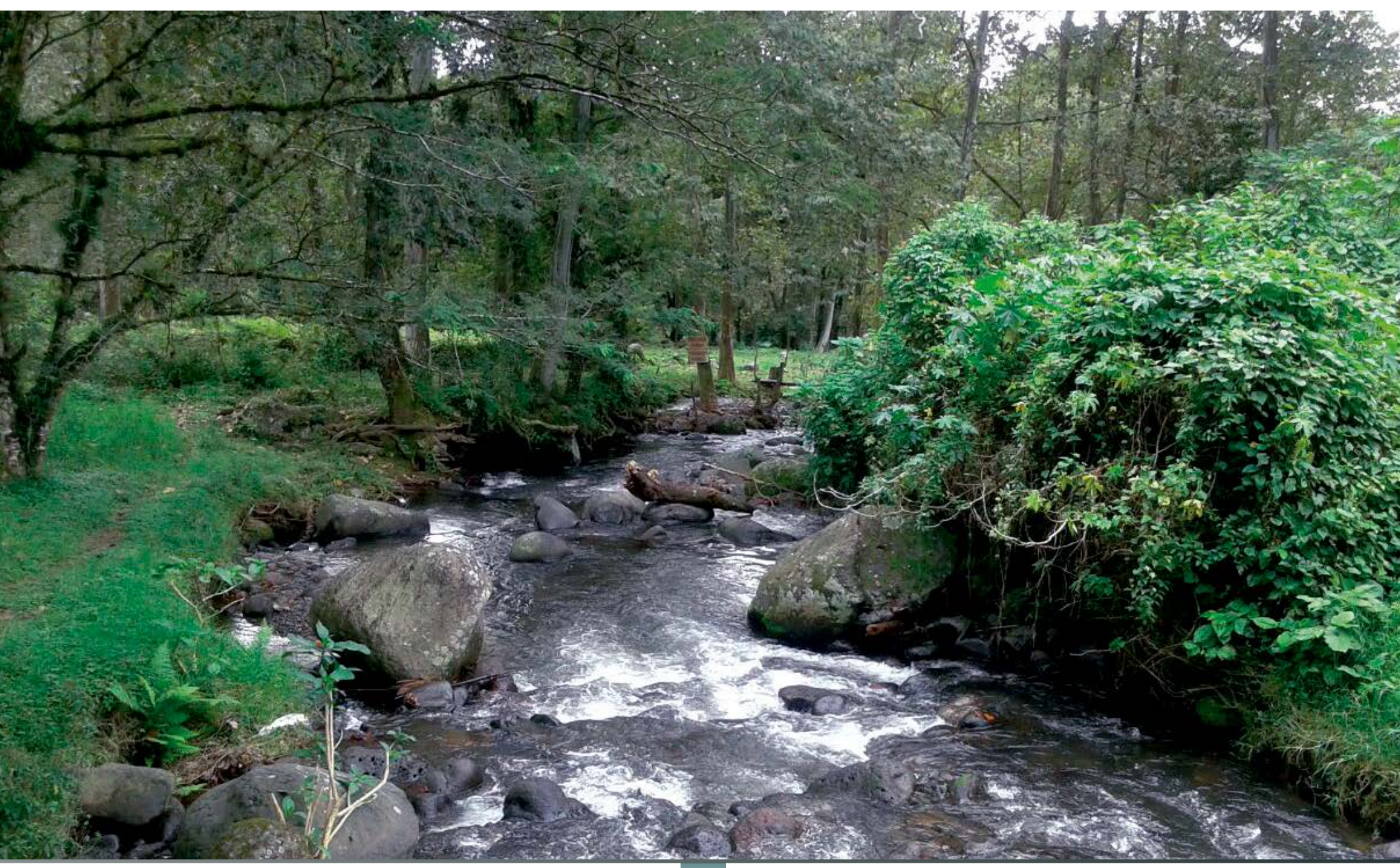


Ya se han presentado varios casos de deshidratación. Pero pese a que el calor es de lo que más se quejan se prefiere más que el frío, siempre y cuando este no sea tan fuerte. Además, los informantes han notado que a mayor calor, mayor también es el frío, especialmente cuando se viene el temporal. Algo de lo que pude ser testigo en el trabajo de campo fue ver el rostro de alegría de los ejidatarios al ver o sentir la lluvia, sobre todo después de varios días de sol intenso; la alegría se contagia en las calles, el parque, y el agradecimiento al creador (quien la envía) se da en todas las iglesias de la localidad.

b) Con relación a los cambios en la actividad agrícola manifestaron que con el maíz estaban acostumbrados a preparar la tierra en abril y mayo y sembrar en los meses de junio y julio (esperaban hasta el 20, si no llegaban las lluvias en esta fecha ya no sembraban), y cosechaban en diciembre. Ahora, las lluvias que cada vez se retrasan y escasean, los han descontrolado por completo en sus tiempos y ritmos. Por ello, buscan no depender solo del cultivo del maíz, sino que se han aventurado a sembrar frijol, chayotes $u$ otras hortalizas; algunos han comprado una vaca, cerdos, aves de corral; otros han dejado las actividades propias del campo y se han empleado en alguna actividad comercial y de servicios o en el trabajo informal en diversas ciudades del país.

Cuando pregunté a los campesinos sobre el clima de ahora en comparación con el que había en la juventud de sus padres, ellos dicen que ya no es igual entre la generación pasada y la de hoy, y básicamente lo señalan con el exceso de Iluvias y sequías en sus áreas de cultivo, así como en lo que ahora producen y las enfermedades frecuentes que sufren con los cambios de clima. Dicen: «... hasta parecemos que no somos de aquí, pues ya no sabemos cómo va estar el calor, si va llover, si va ser frio, parecemos fuereños» (Carlos, 76 años, pentecostal); "ya no podemos predecir el tiempo pues de repente caen unos aguaceros de todo el día, con vientos fuertes que tumban nuestros techos, muchos de ellos acompañados con granizos de gran tamaño, afectando ya no solo los cultivos, sino nuestros hogares» (Hilario, 88 años, testigo de Jehová).

Entre los campesinos se suma a sus preocupaciones la incertidumbre de si conseguirán el alimento para los pocos animales con que cuentan (vacas, burros, cabras, caballos y gallinas), a los cuales hay que proveerles agua y alimento. Muy frecuentemente se presentan temperaturas por arriba de los $35^{\circ} \mathrm{C}$, que no permiten el trabajo agrícola. Me hicieron mención que al estar las plantas expuestas a la intensidad de los rayos del sol, estas se secaban y si acaso aguantaban «la calor», los rendimientos eran ínfimos. Me hicieron notar también que las plantas 
nocivas a los cultivos, curiosamente, se han hecho más resistentes al calor y al uso de herbicidas; refirieron que el herbicida más usado es «La Faena». Una cuestión importante de señalar es que en opinión de quienes trabajan la tierra, el uso de los químicos es lo que más ha afectado la producción en los cultivos, principalmente de papaya, maíz, frijol, mango y otros frutales. Afirman que «tanto químico que se le metió a la tierra y las plantas que quemaron nuestras parcelas trayéndonos plagas a los cultivos de papaya, mango y tamarindo, todo por no trabajar con la moruna (el machete) y el azadón para quitar la maleza y querer producir más» (Gustavo, 63 años, católico).

Algunos campesinos coinciden en señalar que desde hace 20 años el maíz y el frijol ya no se dieron como antes: «Ahora ya casi no se trabaja en el campo porque ya es poco lo que llueve, antes salían carros cargados de maíz, y se cocinaba con los olotes del maíz y ahora solo con leña y eso si la consigue uno» (Anselmo, 71 años, católico).

Debido a lo anterior, ya solo alcanza a verse uno que otro papayal en los campos de cultivo; con el mango pasó lo mismo, solo se tienen algunos árboles, especialmente en sus predios donde están sus viviendas que les sirven para darse sombra. Una esposa de ejidatario me hizo el siguiente comentario: "Yo me di cuenta que el tiempo ha cambiado porque el aguacate que tenemos en la casa, antes daba mucho y desde hace ocho años por tanto calor que ya no» (Petra, 65 años, católica).

Los habitantes cuentan que ha habido fuertes precipitaciones como el ciclón de 1955, que acabo con muchas casas. También han tenido varios huracanes y lluvias intensas, las calles se inundan, y tienen que andar en el lodazal; afortunadamente no recuerdan eventos dramáticos de pérdidas humanas, pero sí cuantiosos daños materiales, ya que el agua se les ha metido en sus casas. Ante toda esta penumbra, los agricultores, cercan sus tierras y las alquilan para pastizales para el ganado, dejando solo poco menos de media hectárea para sembrar maíz, frijol y chile para el consumo familiar. Otros, ante el poco trabajo, tienen que salir a buscarlo lejos de allí para poder pagar las deudas. Otros más han vendido parte de sus tierras de cultivo para poder subsistir. "Con que tuviéramos sol y Iluvia todas las siembras se darían, pero como no tenemos lluvia segura por eso no nos arriesgamos a sembrar nada, sembramos solo pasto pal ganado ese sí es más resistente al calor y no perdemos lo invertido» (Toño, 66 años, pentecostal).

Como podemos ver, los informantes están conscientes de los cambios y riesgos que pueden provocar los sucesos climáticos, así como de sus efectos en la 
salud, en las parcelas y en la forma en que han impactado en la organización de sus actividades, costumbres y modos de vida. Si bien han desarrollado respuestas con sus propios medios, adaptándose a nuevas formas de producción y de trabajo, así como nuevas concepciones de manejo del tiempo, estas no son lo suficientemente seguras para dejar de preocuparse. En las entrevistas me percaté de la incertidumbre que envuelve el ambiente cotidiano. Por ejemplo, el 9 de marzo de 2014 se soltó un fuerte viento (surada) que levantaba los techos de lámina de las casas, y al preguntar sobre el fenómeno, un anciano me dijo: «Este tipo de vientos generalmente se presentan dos veces al año y lo lamentable es que no sabemos el momento y la intensidad de su fuerza y si nuestras casas, lo que sembramos, incluso, si nosotros mismos nos podrá afectar en nuestra salud» (Anselmo, 89 años, católico).

Se vive siempre en alerta por cualquier eventualidad. Algunas veces con miedo de que llegue algún evento climático que los haga cambiar de planes. Un comerciante informal que vende a la orilla de la carretera me comentaba que dependiendo de cómo vaya a estar el clima él planifica su actividad comercial de un día para otro; si hace calor se organiza para vender paletas, raspados y refrescos, y si hace frío prepara tamales, café y surte pan para vender. Algunas veces, por la inestabilidad del clima, ha tenido que cambiar repentinamente y dejar lo que había preparado.

Por cierto, que la mayoría de los pobladores, especialmente los ancianos, están siempre pendientes del pronóstico del tiempo por radio y por televisión, aunque la mayoría opinan que no siempre son certeros y que por lo regular se equivocan. Para los testigos de Jehová, el tema de cambio climático es perfecto para iniciar una plática y lograr introducir su mensaje religioso. Incluso, yo como investigador utilicé el tema del clima como forma de inicio de conversación para lograr introducirme y acceder a la información.

c) En cuanto a los cambios en sus estilos de vida, gran parte de los pobladores han empezado a usar sombrillas y a evitar salir en horas en que el calor se hace más intenso, dejando las actividades fuera del hogar para cuando el sol haya bajado de intensidad. Por ejemplo, se están levantando a las cuatro o cinco de la mañana para ir a sus parcelas y regresar a las 12 del día, para comer y hacer labores en el hogar o en lugares sombreados. Después de las cuatro de la tarde, cuando el sol ha bajado, vuelven a sus parcelas hasta declinar el día (a las seis o siete de la tarde), para al otro día seguir la misma rutina. 
Un malestar generalizado entre toda la población es por la abundancia de zancudos, especialmente en la noche. Señala Domingo, de 79 años, de la iglesia Árbol de vida que: «muchos tuvimos que poner mosquiteros en ventanas y puertas para que pudiéramos dormir, algunos siguen usando el pabellón en sus camas, otros han instalado aire acondicionado ya que con el aire frío se espantan especialmente los chaquistes, que son muy chiquitos y molestos».

Achacan también al calor plagas de piojos, chinches, gusanos que les provocan infecciones en la piel y los obligan a ser más cuidadosos en su higiene. Algunas casas ya las están haciendo más altas para que entre mejor la ventilación y con ventanales grandes para que circule mejor el aire. Hay quienes dicen que con el aumento del calor se han vuelto malhumorados, más desesperados, agresivos y preocupados, porque no pueden realizar sus actividades como se requiere. "Antes la gente de aquí nos respetábamos más, por ejemplo, si había un velorio y había baile, este se cancelaba porque había un difunto. Ahora, puede haber un baile y un velorio en la misma cuadra y no se cancela» (Maura, 69 años, testigo de Jehová).

También me comentaron que han cambiado sus formas de convivencia, pues con el calor ya no dan ganas de salir, temen asolearse ya que les salen manchas en la piel. Sin duda uno de los cambios más visibles es el aumento en el consumo de refrescos y cervezas, y con el frío la venta del café y bebidas embriagantes.

Vamos patrás, en vez de ir padelante, todo está cambiando, antes comíamos con cinco pesos, ahorita ya no es posible. Si no teníamos para comprar, salíamos al monte a cortar quelites, yerbitas, a cazar jabalí, tlacuache, matábamos una gallina, cortábamos naranjas, cocos, teníamos todo a la mano, plátano, papayos, aguacate, maíz para hacer la gorda, el frijol para echarle tomate, chile para la salsa, y comíamos muy bien; por eso poco nos enfermábamos, ahora con nuestra alimentación deficiente no salimos de con el doctor. Y todo cuesta. Por ello, la gente busca una entrada segura de dinero y salen a trabajar lejos, para poder mantener a sus familias (Hilario, 72 años, católico).

De acuerdo con la información de campo (véase cuadro 1) encontramos que, en los últimos 78 años, según la memoria histórica de los pobladores, ha habido estos sucesos climatológicos: 13 sequías, en cinco ocasiones ha habido fenómenos relacionados con las inundaciones: un ciclón, una lluvia que duró 15 días y otra que duró 40 días, una tromba y una granizada. Obviamente, ha habido más, pero fueron de menor intensidad o bien solo se recuerdan las que tuvieron mayor impacto en gran parte de la población afectada. Otros fenómenos mencionados 
por los informantes ocurridos en la localidad son: un tornado, dos temblores y nortes.

Las plagas y enfermedades fueron los sucesos más presentes en la memoria de las personas de edades avanzadas, por lo menos en los últimos 89 años, en la localidad. En siete ocasiones ha habido plagas como las de las langostas, la del gusano medidor, piojos, pulgas, chinches y moscos. En 13 ocasiones señalan enfermedades o epidemias como sarampión, niguas, fiebre tifoidea, tuberculosis, tétanos, alferecía, cólera porcina, popochas (nombre común de la varicela), salmonelosis, dengue clásico y hemorrágico, y actualmente se están presentado varios casos de cáncer, diabetes y chikunguña.

Cuadro 1: Acontecimientos climatológicos y consecuencias en el área de estudio.

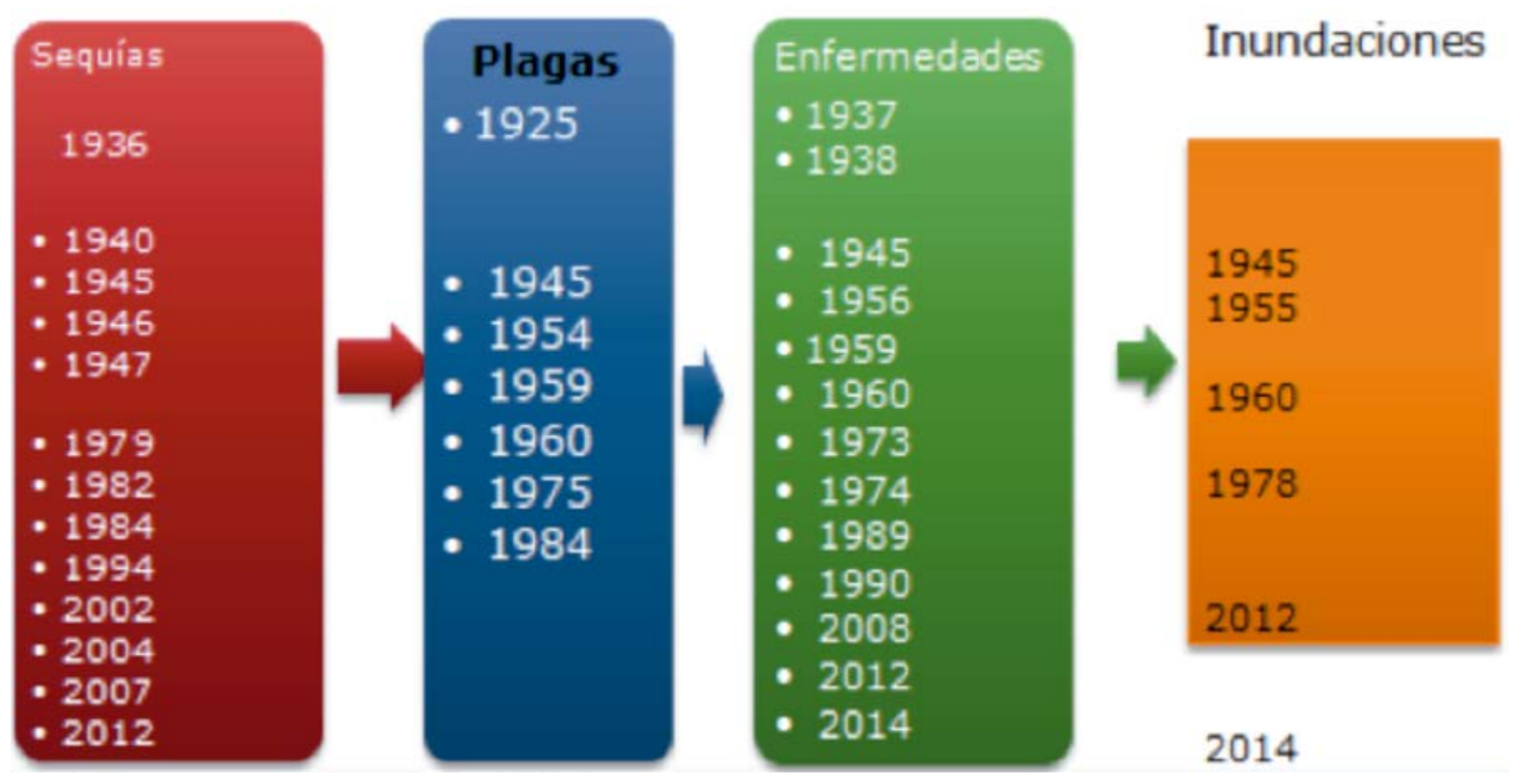

Fuente: Elaboración propia en trabajo de campo, 2015

Como se puede observar hay una percepción teórica y práctica de los acontecimientos climáticos locales, y una memoria histórica que recuerda los efectos y cambios en su espacio, en sus cultivos, en sus actividades cotidianas, en su cuerpo, en su salud. Me sorprendió que a pesar de que tienen conciencia de que será muy difícil que vuelvan a tener un clima favorable, igual al que tuvieron sus ancestros, aun así, les gustaría volver a vivir en este mismo lugar si volvieran a na- 
cer. Poco más de la mitad manifestó que solo un milagro de Dios podría restaurar el clima y el medio ambiente de los daños que el hombre ha causado.

\section{VARIABILIDAD CLIMÁTICA Y PERCEPCIÓN}

En el trabajo de campo percibí que los ancianos sistematizan, ordenan y plantean su forma de vivir, pensar y actuar, tanto en el mundo natural como en el imaginario, identificando sitios de continuidad y discontinuidad, ambigüedad y diferencia.

Lo anterior resulta evidente a partir de la información que arroja el trabajo de campo, pues muestro que: $58.5 \%$ de los entrevistados tuvieron una percepción de la variabilidad climática ligada a los efectos negativos que esta ha tenido en su salud. Especial atención se dio a las infecciones respiratorias, y un poco menos a las estomacales e infecciosas. Pero, curiosamente, $41.5 \%$ mostraron inclinación por asociar la variabilidad climática con cuestiones éticas y religiosas que ubican al hombre como culpable de este desorden en la naturaleza. Por ejemplo, me contaron que en una ocasión en que la lluvia se retrasó muchísimo, la gente llevó a sus santos a los campos de cultivo y los dejaron ahí hasta que realizaron el milagro. Actualmente, los campesinos del lugar ya no hacen estos ritos, a menos que haya una gran calamidad. Con frecuencia, cuando no aparecen las lluvias y se percibe que las milpas estén en peligro, se organizan familiarmente y llevan una cruz a la parcela con la finalidad de que la divinidad ampare sus cultivos. El 15 de marzo se celebra la «misa de bendición de las semillas», y las familias católicas campesinas llevan en tenates una muestra de las semillas (maíz y frijol, principalmente) que cultivarán, con la esperanza de que así tendrán una buena cosecha. Cuando hay fuertes lluvias todavía se encuentran creyentes que van a las iglesias para pedirle al que «quita el agua y pone el sol», San Isidro Labrador, que restaure el clima. ${ }^{18}$

En los no católicos encontré que es a través de la oración de fe y el ayuno como un creyente puede pedir al «creador» les conceda misericordia y traiga la Iluvia o calme la tormenta, mitigue el exceso de calor o intervenga en cualquier otro fenómeno natural, para que este no provoque daños o desgracias entre la población, especialmente en su salud y sus cultivos. «Él siempre nos escucha,

\footnotetext{
${ }^{18}$ Descripciones similares ha encontrado (Juárez 2013, 2014) en el centro del país.
} 
para Jehová nada es imposible. Con una inmensa fe, todo se resuelve, porque Él siempre es bueno con nosotros» (Armando, 67 años, testigo de Jehová).

Una parte central en el pedimento de la oración y el ayuno, es confesar la desobediencia y la falta de sensibilidad a su palabra, proponiendo a Dios cambiar sus modos de conducta y pensamiento.

Dios manda lluvia a nuestra tierra y derrama de tu espíritu entre nosotros, extiende el rocío de tu amor y tu misericordia a nuestras vidas. Dios, nos humillamos ante ti, queremos buscar tu rostro, inclina tu oído y perdona nuestras rebeliones, sana nuestra tierra, sana nuestra tierra, oh Señor, y permítenos tener buena cosecha (oración en el culto del domingo a mediodía en la iglesia Árbol de vida, hecha por un campesino del lugar, 60 años aproximadamente).

La lógica que pude percibir en las entrevistas a profundidad es que siempre los informantes se movían en una dualidad que iba de reafirmar que «somos mayordomos» de lo que Dios creó, y por otra, de soslayar la profecía apocalíptica de la destrucción de «la creación», especialmente en los creyentes no católicos. Es decir, la narrativa que se genera en torno a los cambios climáticos analiza e interpreta no solamente la relación de un pasado local, sino también proyecta una relación del presente con un futuro predeterminado y anhelado.

Dios nos encomendó el cuidado de esta tierra para que tuviéramos que comer (Alicia, 69 años, católica).

Ya estamos al final de los tiempos y nos falta ver todavía lo peor: hambres, guerras, terremotos. El mundo se acabará con lumbre, donde será un inmenso pesar. Todo se encenderá como estopa y se quemará; y todo aquel que no se ha arrepentido se irá al infierno, que está debajo de la tierra que es un lago de azufre ardiente (Abraham, 63 años, iglesia del MIEPI).

En la biblia todo está escrito, nada es nuevo, solo que la gente no sabe, no escucha su palabra, por ello debemos leer su palabra y conocer a Dios y darle gracias por el sagrado alimento, para que este sea bendecido y no nos falte; asimismo pedirle por el clima para que sea benéfico (Efrén, 73 años, testigo de Jehová). ${ }^{19}$

Solo con la fe puesta en el Señor y confiando en su infinito poder y misericordia es como se logrará que las parcelas de cultivo sigan dando de comer a nosotros y a nues-

\footnotetext{
${ }_{19}$ Pese a que se me dijo que todo estaba en la Biblia, cuando les pregunté si había pasajes bíblicos que hablaran sobre el cambio de los climas, ninguno de los informantes dijo conocer ningún versículo, pero sí aseguraron que les ayuda a prevenir todo lo que va pasar a consecuencia del pecado. Esto fue para todos los grupos religiosos.
} 
tros animalitos, aunque hay que estar conscientes de que ya todo esto acabará (Sara, 67 años, iglesia Árbol de vida).

La fe de los creyentes ancianos se centra en la esperanza en que Dios no los abandonará, «porque, como dice Apocalipsis 21:1, ${ }^{20}$ han creído en sus promesas, especialmente en la vida eterna, bajo un cielo nuevo y una nueva Tierra».

La creencia es que todo será hecho nuevo y perfecto. ${ }^{21}$ Toda la creación, según los informantes, estará nuevamente en las manos de Dios, y esto incluye el tiempo de Dios «KAIROS», la eternidad.

Todo estará bajo control divino solo es cosa de confiar absolutamente en sus promesas (Enrique, 64 años, MIEPI.

Dios no nos dejará ni tampoco permitirá que se quite todo lo que produce la tierra (Martha, 66 años, MIEPI).

Por ello, poco preocupa a los creyentes qué condición climática se presente en el futuro. Ahora, si bien la vida y el bienestar dependen de Dios, la forma de vivir (en pecado) 22 ha ocasionado estas implicaciones climáticas. «Dios perdona, pero la naturaleza no [...] Él no manda los calores, ni los huracanes, ni las inundaciones o los fríos, lo hace la propia naturaleza, es la que se está cobrando lo que nosotros estamos haciendo con ella. Dios solo deja que la tierra se defienda de todo lo que le hacemos» (Juan P., 78 años, iglesia Árbol de vida).

Hubo solo tres creyentes que nos refirieron que el pecado no tiene nada que ver con el clima, aunque sí con la falta de conciencia y cuidado del entorno: «creo que no tienen nada que ver nuestros pecados con el clima, porque estos cambios del clima ya hace tiempo que se vienen dando. Pero de que va a seguir aumentado el calor, cada vez más eso va a ser mayor... Los cambios del clima son originados por la contaminación, especialmente la tala de árboles y porque ya somos muchos» (Jesús, 89 años, católico).

\footnotetext{
${ }^{20}$ Nuevo Testamento de los Gedeones Internacionales, versión 1988

${ }^{21}$ La esperanza del futuro perfecto que se espera al final de los tiempos es diferente entre los grupos religiosos. Mientras para los testigos de Jehová este mundo será restaurado de todos sus males, para los del MIEPI este mundo será destruido con fuego y todo acabará y se vivirá en el cielo con calles de oro y mar de cristal. Para los de la iglesia Árbol de vida y para los católicos viviremos en un mundo igual a la Tierra pero en otro lugar que Dios tiene preparado, quizás en otra galaxia o planeta.

22 El abuso de los recursos naturales del planeta que se ha ido dando en los últimos 100 años, especialmente la avaricia, el individualismo, los intereses de crecimiento económico, ha llevado a la variabilidad climática.
} 


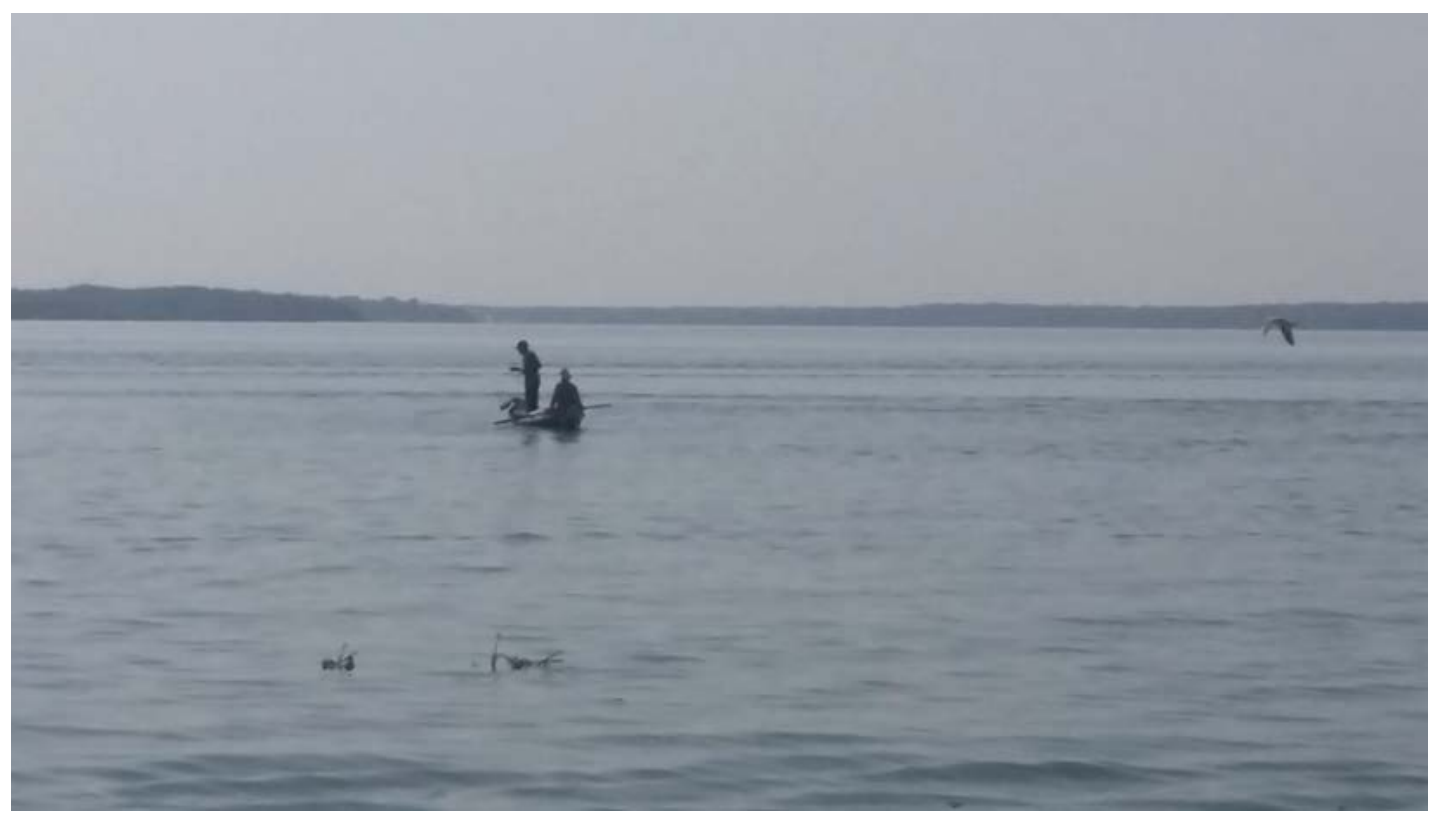

Entre los informantes hombres $20 \%$ piensan que si los cambios climáticos continúan afectando a la agricultura repercutirá en su dieta y estilo de vida.

Tendremos que cambiar las tortillas y los frijoles con el quesito por alimentos enlatados. Aunque quizás este cambio haga a las mujeres más flojas pues algunas ya no quieren meterse a la cocina y preparar los alimentos, solo puras cosas que ya están hechas, como las sardinas, y no quieren hacer tortillas, nos dan puras compradas, ahorita ya todo lo venden nomás para comérnoslo, así como viene. Todo eso va a ocasionar que compremos los alimentos más caros» (Jesús, 89 años, católico).

Y 99\% de esa población masculina tiene poca expectativa en la ciencia y la tecnología para revertir los efectos que han originado los cambios de clima en su localidad. Piensa que si hubiera una solución esta ya se hubiese dado. Se cree que entre más tiempo pase, más difícil va ser la solución. Don Nacho, de 76 años, pentecostal, piensa que «la ciencia, por el contrario, solo hace cosas para aumentar la contaminación». Esta misma proporción de informantes opina que sería imposible soportar todos estos cambios en el clima «sin el cuidado, la misericordia y el amor de Dios». Por lo que una respuesta frecuente fue: el resignarse a la voluntad de Dios y pedirle que perdone los pecados, para que mantenga su misericordia. «No nos queda otra, más que acostumbrarnos, uno ya está viejo, tenemos que aceptar lo que Dios mande, así sea calor o mucha agua. Solo Dios 
sabe qué nos quiere dar; puede que Dios deje que permanezca este clima por muchos años» (Sebastián, 69 años, testigo de Jehová).

Pese a la confianza que tienen en que Dios los ayudará a salir adelante de cualquier vicisitud, $77 \%$ piensan con incertidumbre en el mañana: «Uno no puede decir que vamos a durar 5 o 10 años porque uno pone y Dios dispone, y a la mejor nosotros pensamos que en el futuro va a hacer más calor y puede que Dios deje un clima templado y que permanezca este clima por muchos años» (Efrén, 73 años, testigo de Jehová).

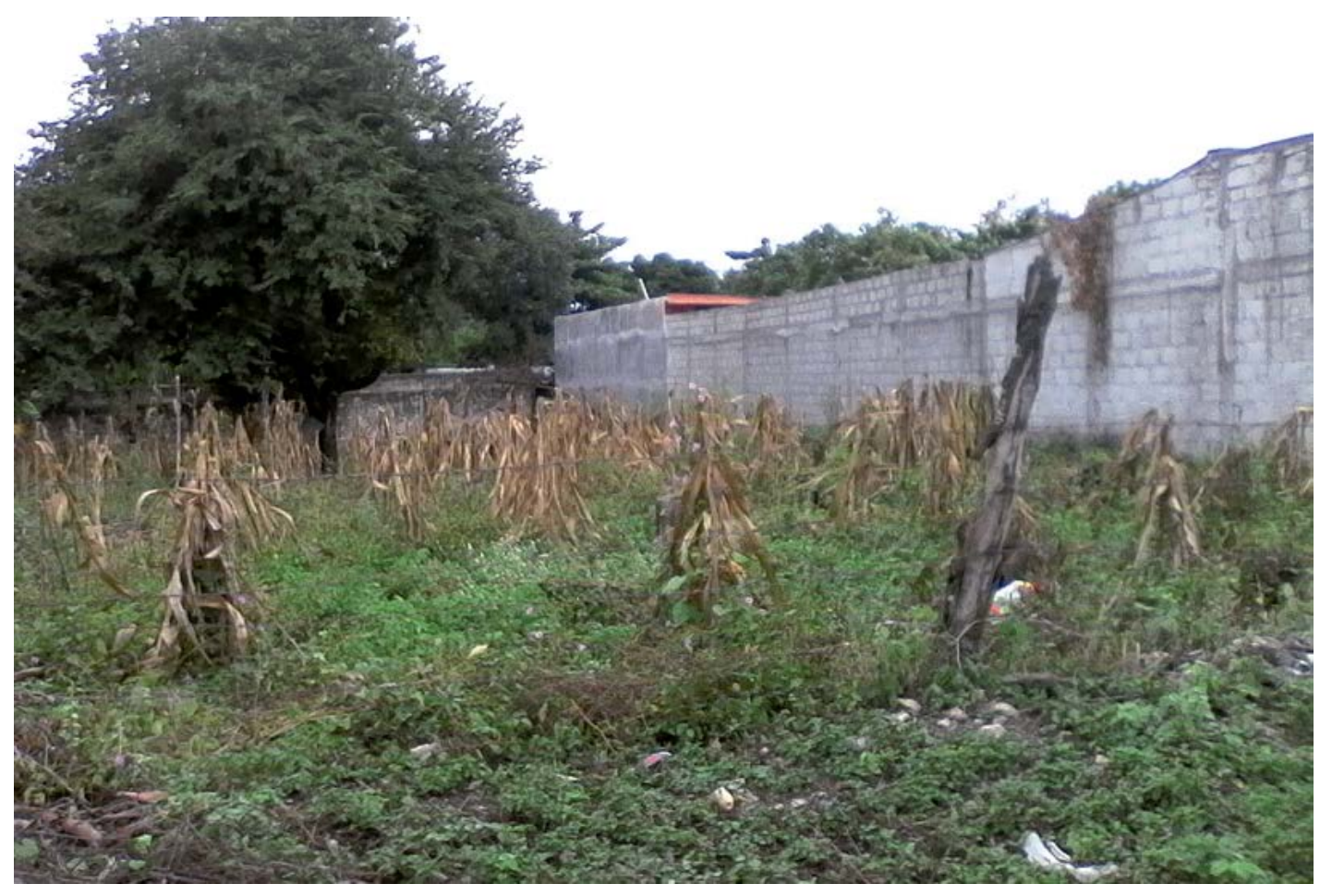

Cuando les pregunté si era un error el haber puesto al hombre como corona de la creación ya que este se ha engrandecido con los recursos que Dios puso a sus pies, los informantes afirmaron que «Dios si bien no se equivoca, sí se enoja porque como humanos no hemos sabido usar los recursos naturales que nos puso a nuestra disposición» (Petra, 78 años, católica).

Un dato curioso que arrojó nuestra encuesta es que $88 \%$ de los informantes piensan que la naturaleza está gobernada por Dios, «porque Él formó los mares, ríos, desiertos llanuras, Él puede cambiar el clima adverso, porque El todo lo puede» (Salustia, 69 años, MIEPI); 9\% piensan que está gobernada por el hombre: «Somos nosotros los que gobernamos la naturaleza, pero como la hemos destruido, hemos roto el equilibrio, ahora no podemos controlar las consecuen- 
cias» (Lupe, 62 años, católico); y $4 \%$ piensan que es manejada por Satanás: «Es el diablo quien nos manda desastres, sequías, inundaciones, solo una persona que elucubra el mal es quien puede mandar tales calamidades, por ello es que se requiere intervención divina para salir adelante» (Dionisia, 78 años, MIEPI).

La totalidad de los entrevistados estuvo de acuerdo en que todas las iglesias deben decir que el daño a la naturaleza es un pecado, y reconocen que los temas ecológicos muy poco son tratados en los mensajes o estudios que sus dirigentes hacen frente a sus congregaciones, especialmente con los jóvenes. Además, consideran que mediante la fe se pueden tomar decisiones individuales y colectivas más razonadas y con mucho más poder y repercusión en la sociedad en favor de acciones que contrarresten, mitiguen el daño causado al entorno. ${ }^{23}$ Casi la mitad dijeron que estas acciones deben partir de un cambio en el corazón del hombre «preparándose bíblicamente con la palabra de Dios»; 38\% consideran que las acciones que emprendan para resolver los problemas del cambio climático deben partir de los dirigentes locales o de gobierno, 14\% piensan que cualquiera puede empezar a hacer acciones en favor de la naturaleza, lo único que se requiere es iniciativa.

En opinión de $90 \%$ existe el riesgo, de continuar estos cambios del clima, de que aparezcan plagas, enfermedades incurables, mala economía, pobreza, hambre y más migración. «Si Estados Unidos está en crisis, pues qué nos esperamos nosotros como pobres. Pero afortunadamente para todo aquel que esté con Dios, Él se encargará de proveer el alimento al hogar. Los que esperan en Jehová no tendrán de qué afligirse» (Ricarda, 70 años, MIEPI).

\section{CONSIDERACIONES Y REFLEXIONES}

Tomando en cuenta las preguntas iniciales que guían la investigación quiero construir ahora algunas consideraciones que nos permitan consolidar la información aquí presentada.

La variabilidad climática, como lo hemos observado, se ha percibido entre los habitantes del área de estudio como sucesos que tienen mucha relación con factores físicos y naturales, así como con cuestiones de índole religiosa y social. De ahí que la percepción sobre la variabilidad climática sea un tema siempre pre-

\footnotetext{
${ }^{23}$ En una plática informal con Gilberto Giménez, epistemólogo y estudioso de los cambios religiosos en la sociedad contemporánea, me comentó que $80 \%$ de los individuos nos dejamos guiar por creencias y solo $20 \%$ por verdades objetivas sustentadas en el método científico.
} 
sente y en constante construcción en la vida cotidiana de los habitantes, a veces como una amenaza natural o material en un escenario físico; a veces como consecuencia y riesgo de las negligencias institucionales, tecnológicas, educativas, culturales, o por la falta de cuidado y de obediencia a las normas éticas y divinas, cuyos efectos trascienden las fronteras generacionales y ponen al hombre ante el desafío de la vulnerabilidad.

El hecho de que la variabilidad climática tenga un fuerte trasfondo religioso no se debe solamente a la incapacidad para controlar, resistir, mitigar o evitar estos sucesos climáticos, sino porque es una construcción colectiva que a través de los años cada persona ha heredado y elaborado al interpretar, valorar, calificar y sentir, especialmente en un cuerpo cansado, agotado por los años y que requiere atención y cuidado.

Lo anterior conduce a analizar la variabilidad climática como un proceso social consciente y específico que se enmarca en condiciones sociales concretas de existencia, generalmente de pobreza, marginación y exclusión, entretejidas fuertemente con una serie de creencias religiosas, recuerdos de lo que hicieron y no hicieron con sus vidas, con valores, aspiraciones, que como individuos y como colectivo tienen. En pocas palabras, hablar de la percepción de la variabilidad climática es conversar de un producto de trayectorias biográficas, las cuales nos centran en la experiencia del habitante y su particular forma de narrar y darle significado a su presente en contraste con su pasado en cuanto a la relación con el entorno. A mi parecer hay cuatro posturas observables:

La evolucionista, que consiste en una tendencia a volver al pasado, donde: «había, se podía, se disfrutaba», y ahora ya no se puede por el daño que el hombre ha hecho la tierra y que es necesario parar y restaurar para que vuelva a ser como antes, o por lo menos ya no continúe el proceso de deterioro. A esta postura se adhieren creyentes ancianos en su mayoría católicos y, en menor proporción, miembros de la iglesia Árbol de la vida, quienes piensan que «Es necesario pedirle a Dios que restaure nuestra tierra, que mande la lluvia, y que nosotros sepamos aprovechar y cuidar» (Tito, 67 años, de la iglesia Árbol de vida).

La nostálgica. Esta postura hace hincapié en que ante un mundo nuevo ya nada se puede hacer, el recuerdo de lo que era antes la localidad, el clima, la vida, no volverá; el daño es irreversible, lo cual provoca una gran tristeza y abatimiento. En este apartado se encuentran la mayoría de los ancianos creyentes de corte pentecostal, quienes opinan que «Hagamos lo que hagamos, este mundo como quiera se va a acabar, Dios no lo ha destruido por su gran misericordia, solo 
Él sabe la fecha y la hora el solo levantará su mano y acabará con todo» (Eliud, 92 años, pentecostal).

La conservadora. Aquí los ancianos se niegan a los cambios y se aferran a sus costumbres, sus tradiciones, sus cultivos, sus espacios, su forma de organizar la vida cotidiana, con el miedo a perder lo poco que les queda. En ellos hay muchísima inseguridad e impotencia al ver sus limitaciones. Generalmente son católicos y testigos de Jehová: «Mire usted, ya somos de edad, ya no podemos andar de aquí para allá, ya no tenemos las mismas fuerzas, solo nos queda seguir trabajando en lo que sabemos, en seguir con la veneración de nuestros Santos, con nuestras fiestas y costumbres. $Y$ esperar lo que Dios quiera para nosotros» (Isidora, 89 años, iglesia del Árbol de vida).

La resiliente, donde el anciano desea trabajar en la prevención examinando los factores de riesgo, y actuando con nuevos aprendizajes, con sentido de pertenencia, transformando las percepciones que tenía y autoevaluándose, proveyéndose de herramientas para poder enfrentar la adversidad y lograr el empoderamiento de las comunidades vulnerables. Aquí se encuentran ancianos tanto católicos como evangélicos, pero en una proporción muy baja.

Estoy seguro que podremos adaptarnos a lo que venga, sea frío o sea calor. Porque estamos seguros de que mientras el verdadero fin del mundo no sea, Dios nos mantendrá y nos sustentará. Mientras tanto, nuestra mirada debe estar puesta en los cielos, donde está Jesucristo a la diestra del Padre y no en las cosas de la tierra» (Libro de Colosenses 3:1-2, Patricio, 73 años, pentecostal). ${ }^{24}$

Ahora, si bien es cierto que hay diferencias escatológicas, ${ }^{25}$ se demostró que la praxis de la fe facilita a los creyentes católicos y no católicos la comprensión de los eventos climáticos, así como les ayuda a establecer su papel y su misión como sujetos históricos, y no solo como habitantes, sino como creyentes cuya tarea, aparte de cuidar la creación, es atraer el poder divino para mitigar, calmar, tranquilizar y comprender lo que está sucediendo y lo que sucederá (especialmente en la segunda venida de Cristo).

\footnotetext{
24 Véase nota 20.

${ }^{25}$ La escatología no es solamente una creencia en un futuro en el cual se cumplirán profecías bíblicas, sino que también es una manera de leer e interpretar la historia y de relacionarse como sujetos en su entorno y en su sociedad, tanto en los conflictos mundiales como en los acontecimientos de la actualidad. Por cierto, dicho sea de paso, en antropología de la religión no conozco investigaciones sobre las narrativas escatológicas.
} 
La preocupación por la variabilidad climática y por el fin del mundo se explica y define por la espera de un futuro predeterminado e inevitable. ${ }^{26}$ Dentro de este contexto, los ancianos entienden estos cambios climáticos como resultado de una decadencia, denigración moral y ética del ser humano, pero sobre todo como un distanciamiento del hombre respecto de Dios, donde los creyentes se sitúan como víctimas, desobedientes y herederos de los errores de sus antepasados, ${ }^{27}$ pero aliados y protegidos por la divinidad y, por lo tanto, con capacidad de ejercer una agencia espiritual que les asegura la victoria y la preparación para resistir cualquier eventualidad climática, hasta el fin del mundo.

Es en los eventos climáticos extremos donde los ancianos se sitúan más cerca de sus creencias religiosas debido a que se sienten más vulnerables para poder controlar, soportar, adaptar, permitir o evitar que tal situación o necesidad tenga un efecto devastador. La fe se vuelve un asidero para mediar la vulnerabilidad, el sentido de indefensión y en ocasiones la proximidad y aceptación de la muerte. Es aquí donde por medio de la fe se es capaz de procesar la experiencia social y diseñar maneras de lidiar con la naturaleza, interceder con la divinidad, activar el poder divino y limitar el alcance de las actividades diabólicas. Por medio de estas

${ }^{26}$ Un trabajo pendiente por hacer está en invitar a futuros investigadores al análisis de estas narrativas y de cómo los creyentes ancianos utilizan su fe para definir su rol dentro de su sociedad, además de cultivar una identidad religiosa y un sentido de agencia espiritual. Por otra parte, es útil señalar que el Apocalipsis predice que el mundo sufrirá un sinnúmero de catástrofes antes de la segunda venida de Cristo a la tierra, en donde se llevará a todos los salvados. Y aquí existen dos vertientes:

Los milenaristas sostienen que Cristo retornará para reunirse con todos los justos y aniquilar a los malos y fundar el reino glorioso sobre la tierra. Él mismo reinará como rey, y todos los justos, incluidos los santos llamados a la vida, participarán en ello. Al cierre de este reino los santos entrarán en el cielo con Cristo, mientras los malvados, quienes también serán resucitados, serán condenados al eterno castigo. La duración de este reino sobre la tierra es considerada de mil años. Al parecer, la mayoría de los creyentes son premilenaristas y creen que la segunda venida de Jesús ocurrirá antes de la inauguración del reino del milenio y de la gran tribulación. Esto es, en la segunda venida de Cristo, los creyentes serán transformados y glorificados en un solo acto, sin tiempos de espera. Así, tanto los unos como los otros serán arrebatados para encontrar al Señor en el aire, acompañando a Cristo en su descenso a la tierra para vencer al Anticristo y la maldad. Inmediatamente empezará el reino milenario de Cristo. Este gobierno con vara de hierro se dará sobre las naciones incrédulas que todavía existan sobre la tierra, donde el pecado (refrenado) y la muerte aún existan, pero donde se vivirá una época de justicia y paz cual nunca ha habido. Antes de terminar este tiempo, Satanás, que ha sido atado para el milenio, será desatado para que engañe a las naciones y para reunirlos para la batalla del Armagedón. Pero será derrotado y enviado a su lugar final.

Cuando el milenio se haya terminado, los incrédulos que hayan muerto resucitarán (recordemos que la resurrección nombrada anteriormente solo fue de justos), para ser llevados delante del gran trono blanco o Juicio Final junto con todos los demás. Allí se escuchará la sentencia final y empezará el estado eterno, cada cual en el destino para gloria o condenación eterna. Sobre escatología entre evangélicos pentecostales recomiendo Lindhardt (2014).

${ }^{27}$ En las narrativas de los creyentes, a partir de la fe, ellos se sitúan a sí mismos en el centro de la historia. 
experiencias se toma conciencia individual y colectiva para continuar en el camino en que Dios los ha puesto. Es por la fe que el creyente evalúa si los cambios climáticos que los amenazan les hacen daño o son dignos de tomar una acción o una preparación para poder evitarlos. En este sentido, creo que desde la fe se puede despertar o activar esa capacidad de procesar la experiencia social (y constituir una agencia espiritual) que propicie nuevos horizontes significativos no solo como creyentes, sino como habitantes de una localidad diseñando maneras de lidiar con la vida, aun bajo las formas más extremas.

Si bien es cierto que la fe no solo consiste en esperar el fin del mundo, sino en crear conciencia y responsabilidad sobre lo que Dios ha puesto en servicio, también es cierto que la fe puede motivar el efecto contrario, de pasividad e incluso indiferencia. Solo cuando se llega a pasar de la fe pasiva a la fe práctica, es cuando se logra crear acciones y participaciones directas.

No se puede ignorar que las situaciones de riesgo y vulnerabilidad están estrechamente relacionadas con la divinidad, y que cualquier situación por la que pasen —sean sequías, inundaciones, terremotos, huracanes, tristezas, dolores, enfermedades o la cercanía de la muerte-, tiene un sentido divino. Incluso todo lo que pudiera parecer negativo es traducido como positivo.

Con lo anterior busco llamar la atención en las narrativas escatológicas y la conformación de una agencia espiritual que nos den nuevas formas de comprensión de los fenómenos naturales, donde podamos vincular lo espiritual con lo social y lo natural de manera holística.

Solamente así podremos entrelazar las esperanzas en la vejez, comprender sus riesgos y vulnerabilidades, penetrar en sus miedos, inseguridades, riesgos, despejar misterios y dejar entrever la validez de su experiencia y el sentido de la vida, en una dimensión donde se revitalicen sus significados y se recuperen sus creencias e identidades; ${ }^{28}$ en fin, donde la vida pueda transformarse en contacto con las verdades y necesidades que no se pueden cambiar, como lo es el fenómeno de la variabilidad climática. ${ }^{29}$

\footnotetext{
${ }^{28} \mathrm{Boff} \mathrm{s} / \mathrm{f}$, señala que los sistemas religiosos e ideológicos consiguen penetrar la mente de las personas y construirlas por dentro, determinando el modo de vivir y de elaborar las emociones, la forma de relacionarse con los otros, con el amor y la amistad, con la vida y con la muerte.

${ }^{29}$ Lamentablemente, antropólogos, sociólogos, psicólogos, geógrafos, médicos, enfermeras, gerontólogos, terapeutas, ministros religiosos, entre otros profesionales, poco interés hemos puesto en la interrelación entre lo natural, lo social y lo espiritual, dejando pocas notas en los informes técnicos y de investigación, que nos lleven a comprender la praxis de la fe en los ancianos y el cambio climático, pese a que existen un sinnúmero de relatos y testimonios sobre esta cuestión. La mayoría hemos tendido a darle la vuelta y considerarlos de manera general como "actos de fe», abstrayendo todas estas experiencias como algo muy específico de un grupo o individuo que se manifiesta en ritos, danzas, cultos, oraciones, entre otros.
} 
Vista así, la variabilidad climática como proceso en construcción constante, es como las mujeres y los hombres entrados en años reestructuran el tiempo con base en el tiempo que les queda por vivir. Aquí es donde los científicos sociales tenemos nuestro desafío, hacer que nuestros sujetos de estudio tomen conciencia de la variabilidad climática. Solo así podremos tener una perspectiva holística, interpretando el pasado, experimentando un presente y prediciendo un futuro, un futuro cada vez más extenso, diversificado y vulnerable.

\section{FUENTES DE CONSULTA}

Aguilar Ros, Alejandra, 2009, «Cuerpo, memoria y experiencia. La Peregrinación a Talpa desde San Agustín, Jalisco», Desacatos, 30, pp. 29-42.

Boff, Leonardo, s/f, « La voz del arcoíris: hacia una espiritualidad planetaria y ecológica», <http://www.olimon.org/uan/Espiritualidad.pdf> [consulta: 21 de junio de 2014].

Cuadernos estadísticos, 1999, Cuaderno Estadístico Municipal. Emiliano Zapata, Estado de Veracruz, México, Gobierno del Estado de Veracruz.

De Celis Carrillo, Ruth, Georgina Hernández Flores, Alejandro Bravo Cuellar y Alfredo Ignacio Feria y Velasco, 2012, «Del cambio climático en la salud», Revista de la Academia Mexicana de la Ciencia, 63(4), pp. 8-17.

Douglas, Mary, 1986, Risk aceptability according to the social science, Nueva York, Russell Sage fundation.

García Acosta, Virginia, 2014, «De la construction sociale du risque a la construction sociale de la prévention: les deux faces de Janus», en Bréda Charlotte, Mélanie Chaplier, Julie Hermesse y Emmanuelle Piccoli (eds.), Terres (dés) humanisées: ressources et climat, Ginebra, Academia-L'Harmattan Editions, pp. 297-318.

Gobierno del estado, 1998, Enciclopedia Municipal Veracruzana, Municipio de Emiliano Zapata, México, Gobierno del Estado de Veracruz.

Hewitt, Kenneth, 1997, Regions of Risk: A Geographical Introduction to Disasters, Londres, Routledge.

Juárez Becerril, Alicia María, 2013, «Los muertos y otros entes divinos populares en la meteorología indígena de ciclo agrícola», Ponencia presentada en la mesa: La Muerte en contextos culturales americanos de ascendencia indígena con una mirada antropológica, en la Universidad Intercontinental, <http://reflexionesinterdisciplinaresmuerte.blogspot.mx/2013/02/ponencia-de-la-dra-alicia-maria-juarez.html> [consulta: 26 de junio 2014].

2014, «Los santos y el agua. Religiosidad popular y meteorología indígena», ponencia presentada el 11 de junio de 2014 en Conmemoración del pensamiento antropológico y obra académica de Félix Báez Jorge, Universidad Veracruzana, pp. $1-12$.

Jürgen, Moltmann, 2004, La venida de Dios: Escatología Cristiana, Salamanca, Ediciones Sígueme. 
Lindhardt, Martin, 2014, «El fin se acerca. Historia y escatología en el pentecostalismo tradicional chileno», Cultura y Religión, VIII(1), pp. 242-261.

Long, Norman, 2007, Sociología del desarrollo: una perspectiva centrada en el actor, México, Colegio de San Luis/CIESAS.

Los Gedeones Internacionales, 1988, El Nuevo Testamento. Versión de Casiodoro de Reina. Revisión 1960, Nashville, Sociedades Bíblicas en América Latina.

Olivares, Barlin Orlado, 2014, "Relación de la naturaleza, el clima y la espiritualidad de las comunidades indígenas agrícolas Kariña del estado Anzoátegui, Venezuela», Tiempo y Espacio, 24(61), pp. 129-150, <http://www.scielo.org.ve/scielo.php?script=sci_arttext\&pid=S1315-94962014000100008> [consulta: 19 de enero 2016].

Ortega y Gasset, José, 1914, Meditaciones del Quijote, Madrid, Biblioteca Nueva.

Rodríguez Shadow, María J. y Robert Shadow Denoma, 2000, El pueblo del Señor: Las fiestas y peregrinaciones de Chalma, México, Universidad Autónoma del Estado de México.

Séneca, 2000, Epístolas Morales a Lucilio I, Madrid, Gredos.

Tejeda, Adalberto, Federico Acevedo y Salvador Velasco, 1989, «Sobre los cambios climáticos», Extensión, 31, pp. 42-48.

Vargas Montero, Guadalupe, 1997, «Venimos a cumplir con la promesa. Las peregrinaciones corporadas de oriente», en José Velasco Toro (coord.), Santuario y Región. Imágenes del Cristo Negro de Otatitlán, México, Universidad Veracruzana, pp. 263-358.

Vázquez Palacios, Felipe R., 2013, «La fe como propuesta de bienestar en la vejez», en Dayse Neri de Souza y Marilia Santos Rua (coords.), Cuidadores informais de Pessoas idosas Caminhos de Mudança, Universidade de Aveiro, pp. 77-281.

Vázquez Palacios, Felipe R., Rodrigo Tovar y Shany Vázquez, 2013, «La percepción del cambio climático que infecciones respiratorias agudas en adultos mayores, algunos casos veracruzanos», Sociedad y Ambiente, 1(2), pp. 75-97, <http://revistas.ecosur. $\mathrm{mx} /$ sociedadyambiente/index.php/sya/article/view/16/27> [consulta: 09 de febrero de 2015].

Welsh, Carlos, 2014, «El cambio climático ya nos alcanzó», Universo, 13(564), pp. 16-17, Universidad Veracruzana, <https://www.uv.mx/universo/general/el-cambio-climatico-ya-nos-alcanzo-carlos-welsh/> [consulta: 10 de febrero de 2015].

Fecha de recepción: 24 de noviembre de 2015

Fecha de aceptación: 30 de marzo de 2016 